\title{
Advancing Discussion of Federal Faith-based Social Service Policies through Overview and Application of Established Health Services Research Models
}

\author{
Michelle D. Garner
}

\begin{abstract}
Since the 1990s, federal policies have allowed public funds to support social services provided through pervasively faith-based organizations (FBOs). Public and academic discourse on these policies tends to be marked by limited data, narrow scope, and the lack of an appropriate analytic framework to adequately consider and critique the merits of the policies, as social workers are compelled to do. The goals of this study are to identify, and preliminarily apply, an established policy analysis model appropriate for use with FBO policy in order to progress discussion. Health service researchers Aday, Begley, Lairson, and Balkrishnan (2004) provide a theoretically based policy analysis framework, which is appropriate for this task and for use by social workers. Their effectiveness, efficiency, and equity policy analysis model is presented along with data and analysis intended to help frame and progress productive discussions on FBO policies within and beyond the profession.
\end{abstract}

Keywords: Faith-based, Andersen behavioral model of health services use, social service policy, religious intervention

\section{INTRODUCTION}

Faith communities have a long-standing, distinguished history of helping those in need. Due to a policy shift in the mid-1990s, federal law currently allows faith-based organizations (FBOs) to provide social services without requiring that they subjugate or alter their organizations' faith identities. Discussion and evaluation of FBO policies and programs have garnered public and academic attention, but are generally limited in scope and predicated on segmented research (Johnson, Tompkins, \& Webb, 2008; Kramer, 2010) and political or religious ideology (Saperstein, 2003; Wineburg, 2007). These analyses are unreliable and problematic because they rely on and perpetuate isolated data and thinking; formal attempts to organize and analyze disparate streams of data relevant to FBO policies are rare and require resources, including the identification of an appropriate framework for such analysis. Yet, according to the Council on Social Work Education (CSWE, 2010), all social workers are obliged, as part of competent professional practice, to critically assess interventions (2.1.3) and use "research-informed practice and practice-informed research" (2.1.6, p. 5) to advocate for improvement of programs and policies $(2.1 .5 ; 2.1 .8)$ that affect their clients and practices. The goals of this study are to identify, and preliminarily apply, an established policy analysis model appropriate for use with FBO policy in order to progress discussion within the profession and perhaps beyond.

Specifically, this study begins by recounting the history of FBOs and FBO policies and the limitations of the current literature. As explained below, current FBO policies are endemic to devolution of social and safety-net services. Social work, as a field, is

\footnotetext{
Michelle D. Garner, PhD, ACSW, LICSW, is an Assistant Professor of Social Work at the University of Washington, Tacoma. Dr. Garner would like to thank the Substance Abuse Policy Research Program (SAPRP) of the Robert Wood Johnson Foundation for grant \#63414 which has provided support for work on this article.
} 
centrally concerned with social justice (CSWE, 2010; NASW, 2008). Therefore, the field is responsible for assessing FBO policies through a lens both sensitive to social justice and compatible with the profession's dominant person-and-environment construction of human behavior (CSWE, 2010) - a construction that posits that human behavior is both influenced and constrained by contexts of the physical and social environment, while also reciprocally impacting the same (Hutchison, 2011). Because a model for such analysis of FBO policies is generally lacking in topical academic and public discussion, the study then contributes to the literature by introducing an established health service research model as an appropriate means for social workers to analyze FBO programs and policies. The model (Aday, Begley, Lairson, \& Balkrishnan, 2004) includes three criteriaeffectiveness, efficiency, and equity — each of which are discussed in turn. The discussion of each criterion includes preliminary, issue spotting application to the states of the science and administrative implementation of FBOs.

\section{THE HISTORY OF FAITH-BASED ORGANIZATION POLICIES}

Communities of faith have long functioned as refuges for those in need, maintaining informal and formal systems of aid. When formalized, such services are traditionally offered one of two ways. Faith communities may maintain auxiliary programs dependent upon membership-derived resources (financial or volunteerism; e.g., a Friday night supper service donated, prepared, and served by members). Faith communities may also give rise to chartered 501(c)(3) non-profit organizations focused upon providing social services, such as Catholic Community Services, the Salvation Army, Lutheran Community Services, and Jewish Family Services; such organizations are maintained at arm's-length distance from their religious roots, may receive government funding, and function subject to standard, prevailing laws.

Traditionally, national policy has sought to protect religious liberty by preventing public funds from flowing directly to religious organizations (such as churches). These "pervasively sectarian" entities, as they are referred to by the Supreme Court, receive tax benefits and engage in worship, proselytization, and religious education. Pervasively sectarian organizations may discriminate in hiring, but historically are barred from direct receipt of public funding based on the rationale that the government should not favor or endorse particular religious views or interests (Saperstein, 2003). However, policymakers have increasingly been swayed toward the competing view that religious organizations providing social services should not be excluded from public funding sources on the basis of faith. Thus, FBO policy began shifting in the 1990s, tracking two trends in national politics: 1) the devolution of social and safety net services downward toward local levels and outward toward private contractors (Hutchison, 2011) and 2) the politicalization of religion (Gelman, Park, Shor, \& Cortina, 2010; McMillin, 2011).

Beginning with the Federal Personal Responsibility and Work Opportunity Reconciliation Act of 1996 (P.L. 104-193) and its extension through the Faith-Based and Charitable Choice Initiatives, federal policy has formally fostered the role of faith communities in the provision of government funded social services, including substance abuse treatment and Temporary Assistance for Needy Families. The significance of these policies is their marked turn in legal and philosophical stance: pervasively religious 
organizations are now able and encouraged to pursue and administer government-funded social services without a requirement that they alter or subjugate their religious identity (De Vita \& Wilson, 2001; Saperstein, 2003). Consistent with national political trends, the policies reflect a desire to enhance the role of FBOs in the provision of public services, a concern for the organizations' religious autonomy, and financial commitments in the form of technical trainings to entice FBOs into the role of service providers. The new FBO policies prohibit proselytizing and seek to ensure the right to religious liberty of service recipients. However, adherence to these protections is neither systematically measured nor enforced (GAO, 2006; Kramer, Finegold, De Vita, \& Wherry, 2005b) and is recognized as problematic (GAO; Kramer et al., 2005b; President's Council, 2010).

In 2001, President George W. Bush pressed this FBO agenda through Executive Order, after Congress declined to legislate (Kramer, Finegold, De Vita, \& Wherry, 2005a). For example, President Bush created The White House Office of Faith-Based and Community Initiatives within the Executive Office, with the goal of expanding the opportunities for religious groups to contribute to public purposes "such as curbing crime, conquering addiction, strengthening families and neighborhoods, and overcoming poverty" (Exec. Order No. 13199, 2001, Sec.1). Eliminating obstacles to FBOs fulfilling his envisioned role was a cornerstone in President Bush's domestic agenda (Kramer, et al., 2005a).

The FBO policy shift has been controversial. Critics have suggested that the Bush administration's policy changes were aimed principally at supporting an evangelical religious agenda (Wineburg, 2007). Most FBO funding goes to Christian-based groups (Green \& Sherman, 2002; Kramer, 2010), which has led to concerns about religious diversity in policy implementation. The constitutionality of President Bush's approach to supporting FBO services has also been questioned (Mink, 2001; Saperstein, 2003), on the basis that these policies establish a government religion and infringe upon an individual's rights to free exercise of religion. Minimally, the collective shifts in FBO policies have been criticized as part of a troubling devolution of public and safety-net services to the private sector (Kennedy, 2003; Mink, 2001; Saperstein, 2003; Wineburg, Coleman, Boddie, \& Cnaan, 2008).

The swing in political power in 2008 suggested some course correction (Pew, 2009). Early in his presidency, President Barack Obama amended Executive Order 13199, abolishing President Bush's Office of Faith-Based and Community Initiatives and replacing it with the President's Advisory Council on Faith-Based and Neighborhood Partnerships ("President's Council"), which advises the President on best practices and needed improvements in the provision of services to vulnerable populations, specifically those who are low-income or underserved (Exec. Order No. 13498, 2009). President Obama also recast the role of government from aggressively eliminating obstacles to FBO funding toward one of measured accountability. President Obama described a need to balance the ability of FBOs to deliver services with the preservation of constitutional commitments, including "guaranteeing the equal protection of the laws and free exercise of religion and forbidding the establishment of religion” (Exec. Order No. 13498, 2009, Sec.1). 
In 2010 President Obama amended FBO policy implementation by enhancing protections to beneficiaries while mandating that "[f]ederal financial assistance for social service programs should be distributed in the most effective and efficient manner possible" ("Principles and Policymaking Criteria," Exec. Order No. 13559, 2010, Sec.2.a). These policies impact the purveyance of social services and the formal role of religious institutions in addressing governmental safety-net services.

The Pew Research Center (2009) reports that Americans indicate having related concerns about: church and state separation (52\%), FBOs failing to meet program standards (48\%), and discriminatory hiring practices (74\% believe FBOs receiving government funding should not be allowed to hire based on religious belief). However, only $25 \%$ of those polled oppose government support of social service programs through pervasively sectarian FBOs. Sixty-nine percent of the American public favors government funding for social services to religious organizations. They believe this enhances service options (78\%) and that non-secular providers "would be more caring and compassionate" than other providers (68\%; Pew, 2009, 7th paragraph).

In 2009, the majority (52\%) of Americans thought religious organizations are best suited to feed the homeless. Thirty-seven percent of respondents generally believed religious organizations are best at helping the needy [compared to non-secular (28\%) or government organizations (25\%)]. This belief is both most prominent and rising among Republicans (56\%, up 16\%) and white evangelicals (60\%, up 13\%; Pew, 2008-2009 comparison). General support for FBO policies is strongest among African-Americans (85\%) and Hispanics (80\%). Whether one personally views changes that allow pervasively religious organizations to directly receive public funding as a needed correction or a deviation from core principles, it remains imperative that policies regarding the provision of social services be focused on the resulting welfare of the individuals and communities served. It is incumbent upon professional social workers touched by the issue to critically evaluate federal FBO policies systematically, through an appropriate theoretical framework as a requisite of competent practice (CSWE, 2010).

\section{FAITH-BASED ORGANIZATIONS AND LIMITATIONS OF THE LITERATURE}

Available FBO service research tends to be segmented. Program evaluations of specific field-based services are prominent in the literature, rather than the controlled experimental studies required for clearer results and causal inferences. It is impossible to determine, in most FBO services research, what part (if any) religious aspects of programs have played when positive participant outcomes are found; or for whom religious aspects detracted from or impeded positive outcomes (e.g., Kissane, 2008). Research illuminating the relationship of religion and health is conducted and discussed separately from FBO research. In sorting through the FBO research literature, it often is difficult to discern program and outcomes research provided through private funding from those provided through government funding.

Existing FBO research can seem contradictory. For example, data from the National Substance Abuse and Mental Health Services Administration (SAMHSA, 2010) suggest 
FBO programs appear very similar based on reports of what is offered when compared to non-FBO programs (e.g., 87.6\% of FBOs and 92.2\% of non-FBOs offer discharge planning; and $76.3 \%$ and $82.6 \%$ offer aftercare/continuing care respectively). Yet more nuanced research such as Sung, Chu, Richter, \& Shlosberg (2010) and Hodge and Pittman (2003) reveal potentially important differences between services provided by FBO and non-FBO addiction treatment programs.

Sung, Chu, Richter, and Shlosberg (2010) undertook a national, randomized study of program characteristics among faith-based Teen Challenge USA (TC; $n=80$ ) programs compared to secular programs $(n=68)$ randomly drawn from the National Directory of Drug and Alcohol Abuse Treatment. TC programs are associated with the Pentecostal Protestant Assemblies of God faith tradition and do not use public funding, but annually offer an estimated 5,000 treatment beds and services worth \$54 million to \$66 million (Sung et al., 2010). These researchers found several notable, meaningful differences between program types, in their conceptual etiology of substance abuse, matrix of on-site interventions offered, and assumptions about human nature. Specifically, respondents in TC settings believed substance abuse is "a consequence of separation from God" and "caused by a lack of meaning and purpose in life," whereas those in secular programs believed it "is a brain disease" and "people are genetically predisposed to drug use" (p. 393). TC and secular programs offered a different constellation of services: "Bible classes (100.0\% vs. 35.3\%), prayer meetings (100.0\% vs. 29.4\%),” (p. 349), “individual psychotherapy ( $0.0 \%$ vs. $41.2 \%)$, group psychotherapy (0.0\% vs. 35.5\%), psychiatric assessment (0.0\% vs. 23.5\%), [and] primary medical care (0.0\% vs. 23.5\%)" (p. 394). Eighty-three percent of TC respondents agreed that "Human nature is fundamentally perverse and corrupt” (p. 392). Only 16\% of the secular providers similarly agreed.

Hodge and Pittman (2003) researched state-registered FBO programs in Texas ( $\mathrm{n}=30$ respondents of 55 possible) and also probed more deeply in their questions and analysis. Program participants in the FBOs received a prominently "salvation transformation" and scripture-based drug and alcohol treatment with no apparent reference to evidence-based intervention or best practices, which would include concerns such as appropriate steppedup levels of care and relapse prevention counseling. Though more than half the providers of these treatments were trained chemical dependency professionals, the majority of FBOs studied had no eligibility requirements for treatment providers. Twenty-five of the FBOs reported having a "follow-up program" for those discharged; the follow-up programs were described as: knowledge of the client's work and church upon discharge $(n=15)$, scheduled phone calls or letters to clients $(n=5)$, and continued participation with the program or church $(n=3)$. These data suggest definitions of important constructs such as discharge planning may differ among FBO and non-FBO substance abuse program respondents in SAMHSA's (2010) research.

SAMHSA's data are from the National Survey of Substance Abuse Treatment Services. The survey items are count or binary derived from check-mark lists to indicate "yes," (e.g., "Which of the following services are provided by this facility at this location ... 14) discharge planning, 15) aftercare/continuing care;” SAMHSA, 2008, p. 3). There appears to be no knowledge base criteria for completing the form on behalf of the facility. If respondents desire clarification on terms used in the survey, the survey directions send 
them to consult a series of WebPages. Thus, definitional differences among survey respondents in "discharge planning and after care" would appear possible and quite likely in light of others' research (Hodge \& Pittman, 2003, SAMHSA, 2010, Sung et al., 2010). This possibility calls into question true similarities across FBO and non-FBO addictions programs.

Such theoretical and substantive differences in services offered are not limited to addictions treatment services. Comparative research among services of a Houston-based community sample of FBO versus secular programs for the homeless also show stark differences (Ebaugh, Pipes, Chafetz, \& Daniels, 2003). Researchers analyzed data from 89 organizations, a 52\% response rate of non-governmental or community development corporations in the 2001 Homeless Services Directory pool. Ebaugh and colleagues determined three notable, germane characteristics of religious organizations. First, religious organizations use more volunteer workers, use religious affiliation in hiring, and view religiosity of staff and leadership as central to their mission. Second, they use religious sources along with secular resources in decision making. And, third, the religious organizations support religious activities with clients such as "praying with a client, promoting a particular religious viewpoint to a client, speaking about spiritual matters to clients, and discussing behavioral issues using religious principles” (p. 422).

FBO service programs are different from secular ones. The core religious nature is obviously different, but understanding and quantifying how this character manifests as content, background, assumptions, or focus of interventions and organizational procedures is complex and not at all obvious (e.g., Cnaan, Sinha, \& McGrew, 2004; Ebaugh, et al., 2003; Jeavons, 2004; Netting, 2004; Sider \& Unruh, 2004; Smith \& Sosin, 2001; Unruh, 2004). Nuanced explanation of how faith is included in FBO programs is complicated and often inadequately addressed in available research literature. What is certain is that currently the Obama Administration intends to continue to promote use of taxpayer money to provide public services through FBOs (Obama, n.d.).

In sum, understanding the role of religion in FBOs and assessing the merits of individual programs and the federal policies promoting their use is challenging. The social work profession views human behavior in the social environment as a dynamic interaction of the person with his or her environment (CSWE, 2010). However, the person-and-environment construction alone is inadequate either to predict service utilization and outcomes or to assess policies affecting them (see Wakefield, 1996). What is needed is a comprehensive, empirically-based framework, congruent with social work values and person-and-environment assumptions.

\section{HEALTH SERVICES RESEARCH}

Health services research is a promising field from which to adopt a comprehensive empirically-based model. Much like social work, health services research is a multidisciplinary informed field aiming to facilitate the health and well-being of people through study and enhancement of health supporting policies and services (see AHRQ, 2009; UW Department of Health Services, 2011). Rather than focus on specific issues or populations, health services research looks at the processes of services; e.g., access and 
entry, provision dynamics, provision mechanisms, content (interventions), site and environmental context, departure or continuance, and costs. The Behavioral Model of Health Service Use (BMHSU; Aday \& Andersen, 1974; Andersen 1968, 1995, 2008; Phillips, Morrison, Andersen, \& Aday, 1998) is highly compatible with the social work person-and-environment construct (CSWE, 2010). The BMHSU captures and operationalizes those interrelated personal and exogenous features, such as site and provider characteristics, that impact an individual's entry, continuance, consumer satisfaction, and future use choices regarding services (see Andersen, 1995, 2008). The BMHSU has provided the conceptual framework for extensive national and international predictions and assessments of health care costs and utilization, including use with and without adaptation in evaluation of specific populations such as homeless people, minorities, women, and the elderly (Ashton, 2008).

As a contributor to the BMHSU (e.g., Aday \& Andersen, 1974; Phillips et al., 1998), Aday and colleagues have built upon and extended the BMHSU to include policy evaluation criteria. The model may be applied for individual-level or population-level policy analyses. Thus, they offer a robust, theoretically-based conceptual framework by which to evaluate health-related policies, including those that are principally social, institutional, or environmental (Aday et al., 2004; Aday et al., 1999). The World Health Organization (Boerma, Chopra, \& Evans, 2009) asserts that a multi-factored framework — such as Aday and colleagues' (2004) effectiveness, efficiency, and equity policy analysis framework - is an important contribution amid efforts to solidify a means of defining and comparing the effectiveness and equity of health care systems. Aday and colleagues' effectiveness, efficiency, and equity policy analysis framework is an established, appropriate, and systematic way to consider FBO policies. It is also compatible with the social work profession's person-and-environment construct and values of social justice and enhancement of community well-being (CSWE, 2010).

\section{THE EFFECTIVENESS, EFFICIENCY, AND EQUITY POLICY ANALYSIS FRAMEWORK}

All social work practice shares the objective of understanding social problems and their potential solutions, but policy considerations introduce a second task: that of translating these understandings into government action (Aday et al., 2004, p. 6). Social workers must thus consider FBO policies on two levels: their scientific support and the pragmatics of implementing them. The sections below first describe each of Aday and colleagues' three policy analyses criteria: effectiveness (quality), efficiency (costeffectiveness), and equity (access). Directly following each criterion description are preliminary literature review data and analyses that highlight issues within the states of science and implementation within that criterion. This initial issue spotting application is intended to demonstrate the utility of the model and to frame and spur, rather than exhaust, further discussion and research. 


\section{Effectiveness}

Effectiveness is a measure of quality. Whereas efficacy reflects the best outcomes found to be possible in a controlled study, effectiveness is the degree to which these possible outcomes are actually attained in the context of practice. Measurements of effectiveness can be drawn from the structural levels of the community, system of care, institution, or patient. On the individual, clinical level, effectiveness is an evaluation of "interactions of patients and providers in the medical care system and institutions and the resulting clinical improvements or health benefits achieved by patients" (Aday et al., 2004, p. 60). Such improvements may be resulting changes in physical, behavioral, attitudinal (beliefs and satisfaction), or patient education measures. Effectiveness is dependent upon the content and dose of an intervention and the context and process of delivering it. Process aspects of care services include actions, dynamics, and individual characteristics of the site, provider, and the recipient(s) at play in the process of service delivery. On a population level, effectiveness is an epidemiology of health. It must therefore take into account both individuals seeking services and individuals eligible for or needing services who do not seek them. It must also evaluate the impact of services and the environment (physical, social, and economic) upon the population's health. Utilization rates (realized access) are an effectiveness outcome from the population perspective that fits conceptually within service processes (Aday et al. 2004, p. 66).

Policy considerations of effectiveness in the clinical-level perspective (focused upon structures, processes, and outcomes) revolve around best practice guidelines and mechanisms for quality assurance or improvement of processes and outcomes, according to Aday and colleagues (2004). Whereas policy considerations from a population-level perspective (focused upon environment, biology, behavior, and medical care) revolve around research to understand and impact targeted issues, prevention efforts, and enhanced access through quantity and dispersion of care services. In practice, populationlevel policy analysis of effectiveness frequently focuses upon community needs assessments and comprehensiveness of an integrated continuum of available care (prevention through follow-up).

FBO service related research. Effectiveness is equivalent to traditional outcomes research (e.g., whether people better off for having the service). The goals of this criterion are to understand: "What services work for whom, under what conditions, when should they be offered, and by which providers?” (Lyons, Howard, O’Mahoney, \& Lish, 1997, p. 1). As previously noted, existing FBO research is scant and problematic (DeHaven, Hunter, Wilder, Walton, \& Berry, 2004; Dodson, Cabage, \& Klenowski, 2011; Johnson, et al., 2008; Kramer, 2010). For instance, a Social Work Abstracts (Ovid) database key word advanced search of (faith, church, congregation, parish, or synagogue) with (program, social service, or social services) and (study or evaluation) conducted March 5, 2012 yielded 69 peer-reviewed articles. Similar, non-mutually exclusive, searches within Social Services Abstracts (ProQuest) and PsychINFO (Ebsco Host) produced 647 and 622 respectively. There are multiple studies suggestive of the merits of FBO programs (e.g., Bartkowski, Call, Heaton, \& Forste, 2007; see Johnson, et al., 2008). However, when actually examining outcomes of a FBO intervention, such studies, as a group, suffer multiple methodological issues such as: poor variable measurement, 
failure to account for intent to treat, lack of randomized control groups (lack of randomized non-faith-based comparison treatment group), failure to account for attrition, and lack of appropriate statistical analysis (e.g., a segmented and limited in scope research base). At present, both the efficacy and effectiveness of FBO programs are still unproven (Amirkhanyan, Kim, \& Lambright, 2009; Cnaan \& Boddie, 2002; Dodson et al., 2011; GAO, 2002, 2006; Kramer, 2010; Wineburg, 2007). There is a lot of work to be done in this area.

Empirically supported theory suggests that contextual, individual characteristics, processes of service delivery, satisfaction of actual or intended consumers, and measureable outcomes are all areas that impact service utilization, and, therefore, program effectiveness (Andersen, 1995, 2008; Aday et al., 2004). They merit research in the context of FBO service provision. Specifically, how elements of religion in service processes, provider contexts, and provider character impact and interact with recipients to affect outcomes and realized access of services remains understudied. How does static religiosity of setting or provider compare in outcomes to services in which religious and spiritual assessment of the client are used to tailor the intervention provided to the client-as is best practice for social services based on professional counseling or case management standards (Cohen, 2009; DHHS-OMH, 2005; Ehman, 2009; Hodge, 2006; Mattison, Jayaratne, \& Croxton, 2000)?

Current FBO policy-related research is inconsistent or absent on multiple counts. Most problematic are service process issues: 1 ) defining and operationalizing content and dose of religious inclusion among the continuum of FBOs and their subprograms (as programs within organizations may vary in religious content and dose between each other and the organization as a whole); and 2) identifying and understanding the active "faith" mechanism that ostensibly makes these programs different from secular organizations and programs (see Kramer, 2010). Looking outside the FBO literature to the body of research exploring religiosity or spirituality and health outcomes quickly indicates that further research on the religion-health relationship is imperative and relevant to FBO policy considerations.

Most of the early and encouraging research that linked religion to positive health outcomes lacked specificity (Hill \& Pargament, 2003). Nuanced research of the last decade works to understand dimensions of religiosity, which is generally now conceptualized as a separate construct that can overlap with spirituality, and how religious and spiritual dimensions relate to outcomes of interest. Contemporary work in this area suggests that religion can be helpful to people, but is far from a global panacea and may actually be deleterious in some cases. Negative religious coping (crises of faith, struggles about meanings or negative self-appraisals in light of theology) as well as interpersonal religious conflicts are linked with poorer, not better outcomes (see Hackney \& Sanders, 2003; Hill \& Pargament, 2003; Sternthal, Williams, Musick, \& Buck, 2010; or Pargament et al., 1998). Religion/spirituality (r/s) research is also now suggesting that meaning or forgiveness, both of which may be derived through religion but neither of which are unique only to religion, may moderate positive effects of $\mathrm{r} / \mathrm{s}$ upon outcomes (Lyons, Deane, \& Kelly, 2010; Park, 2007; Sternthal et al., 2010). Mental health status may (Webb, Robinson, \& Brower, 2011) or may not (Edlund et al., 2011) play a 
mediating role in the forgiveness pathway relationship. Others' work suggests that positive benefits of $\mathrm{r} / \mathrm{s}$ may stem from triggering of beneficial relaxation or meditation mechanisms (Seeman, Dubin, \& Seeman, 2003; Seybold, 2007), which can be subsumed in $\mathrm{r} / \mathrm{s}$ practice but are also not unique to $\mathrm{r} / \mathrm{s}$. Many think social support derived from shared religious practice is at least part of the active agent linking religiosity to outcomes (Powell, Shahabi, \& Thoresen, 2003).

Religion is also not universally linked to pro-social behavior, but, in fact, can foster in-group/out-group dynamics detrimental to the greater community, such as greater prejudice and harsher treatment to out-group members (Hall, Matz, \& Wood, 2010; McKay, Efferson, Whitehouse, \& Fehr, 2010; Preston, Ritter, \& Hernandez, 2010). Religion can also be detrimental to in-group members when their identity is in conflict with their communities' religious teaching, most obviously with lesbian, gay, bisexual, and transgendered community members (Blackwell \& Dziegielewski, 2005; Levy \& Reeves, 2011; Rowatt, LaBouff, Johnson, Froese, \& Tsang, 2009; Sherry, Adelman, Whilde, \& Quick, 2010; Whitley, 2009). It should be noted that all major allied health professional organizations oppose "reparative therapy" or "sexual orientation conversion therapy," even with youth (Just the Facts Coalition, 2008). Again, there is a pressing need for research to discern the mechanisms by which $\mathrm{r} / \mathrm{s}$ affects health outcomes, and for whom, in what context, and in what dose their use is helpful or harmful.

There are additional processes of FBO service features that also specifically need research attention. The policy amendments enacted by the Obama Administration, Principles and Policymaking Criteria (Exec. Order No. 13559, 2010), seek, in part, to correct some of the processes-of-service related concerns discussed in the President's Council's report (2010); e.g., contention about religious icons in rooms used for government-supported programs, insufficiency of notice of non-religious alternatives to services, need for adequate separation in time and location between government-funded programs and the overtly religious programs of the organization, lack of proper training for providers around all identified issues, and lack of checks for policy adherence. Research will be required to discern the progress made on these fronts.

Work to explore FBO service provider contexts and individual consumer characteristics is further along. Conceptual work toward defining the widely varying sources and gradations of religiosity inherent in FBO services is progressing (Ebaugh, et al., 2003; Jeavons, 2004; Smith \& Sosin, 2001). There are initial literatures about characteristics of service-providing FBO organizations (e.g., Chaves \& Tsitsos, 2001; Cnaan, Sinha, \& McGrew, 2004; Ebaugh et al., 2003; Hodge \& Pittman, 2003; Sung et al., 2009; Tangenberg, 2005) and service recipients (Heslin, Andersen, \& Gelberg, 2003; Sager \& Stephens, 2005; Wuthnow, Hackett, \& Hsu, 2004). It appears from empirical evaluation that those using FBO services have different characteristics or needs than those seeking services elsewhere (Heslin et al., 2003; Reingold, Pirog, \& Brady, 2007; Wuthnow et al., 2004). In part, this may be due to FBO providers formally or functionally barring service access to some people based on their characteristics, such as criminal histories or lifestyle choices (e.g., Cnaan et al., 2004; Reingold et al., 2007). Even some of those who do use FBO services do not like the religious aspects (Kissane, 2008; Sager \& Stephens, 2005). Limited access to, dissatisfaction with, or avoidance of 
FBO services are all differences in realized access (utilization and customer satisfaction) across groups that also have equity implications.

It is also very likely that FBO program effectiveness may vary with the goals of services being provided. Dehaven and colleagues (2004) conclude from limited data that it appears FBO programs can be successful community partners in a patient education role (e.g., helping to increase knowledge of diseases, increase screening behavior, and decrease risk behaviors). Future research should consider if FBO providers may have different results delivering content that is less likely to be stigmatizing or have moralistic framing (e.g., the importance of breast cancer screening compared to addictions treatment). Again, there are multiple research agendas related to clarifying and establishing the evidentiary effectiveness of FBO social services. Research by O'Connor and Netting (2008) among diverse "exemplar" FBO programs underscores challenges to effectiveness research with FBOs, whose providers prioritize "the faith factor" (p. 354), flexibility, stewardship, and commitment to multiple stakeholders over protocols or evidence-based outcome measures.

FBO policy implementation considerations. From the above discussion, it would follow that policymakers and social workers should be contributing support and efforts for quality research on topics related to FBO service provision that will be required to determine effectiveness of FBO programs. Lack of current research about the difference between secular and religiously-based social services, and the effectiveness of FBO programs in particular, puts administrators in a difficult position. Administrators have Presidential mandates to distribute funds for social service programs in the most effective and efficient way possible, while also being non-discriminating on the basis of religiousness of applicant organizations (see Exec. Order No. 13559, 2010). Yet, they are without benefit of the knowledge needed to discern if and how these mandates can be simultaneously met. Also on a population level, administrators and policymakers should be considering local needs assessments and the strength and integration of needed services.

President Obama's recent amendment to Executive Order 13279 has called for better accountability in assuring that federally supported social service programs adhere to his revised fundamental principles for partnerships with FBOs and other neighborhood organizations (Exec. Order No. 13559, 2010), and for related guidance documents for use by supported programs. Thus, municipalities should look for best practices and quality assurance guidelines for administration of funds and services for publicly funded FBO programs. Such guidelines are aspects of individual-level effectiveness policy criteria (Aday et al., 2004), and indicate that policy implementation is effectively progressing, ahead of, and despite troubling gaps in, the evidentiary science.

\section{Efficiency}

Efficiency is achieved through proper production and allocation of health care services and goods within the constraints of limited resources (Aday et al., 2004). Thus, efficiency deals with the marginal cost for incremental health improvements and has a goal of maximum benefit of the population's health, relative to the costs to accomplish it. 
Allocative inefficiency can occur when resources are put into the wrong, or wrong mix, of goods or services, such as ineffective programs or programs targeted at the wrong level (prevention, primary, tertiary). Discussions of need (when someone is both better off with the service and values it) and consumer demand (consumption of services at given costs to the recipient) enter these debates with the former usually driving regulatory allocations and the latter driving for-profit provider and market-based actions. Production inefficiency occurs when the cheapest means of acquiring goods or services are not used. According to Aday and colleagues (2004), factors that impact production efficiency include using the least sufficiently qualified persons to perform health care system roles, and optimizing economies of scale, service sites, and payment methods.

Determination of production efficiency is predicated upon determination of allocative efficiency, which is predicated upon determination of effectiveness. In other words, while a given actor may successfully buy goods and services as cheaply as possible, inefficiency occurs if the purchased goods and services are ineffective. Evaluative tools used in determining efficiency draw heavily from economic theory and methods and include analyses of cost-benefit, cost-utility, cost-effectiveness, and comparative systems.

Policy considerations within the area of efficiency include: 1 ) the overall health care target budget as proportion of state or nation's gross domestic product (allocative); 2) creating a "mix of services that maximizes a combination of positive health outcomes and consumer satisfaction for the available share of resources expended on health services" (Aday et al., p. 175; allocative); 3) "considerat[ion of] the health of individuals receiving care, their satisfaction with the method of service delivery, and any health consequences to others who may be indirectly affected by health programs” (Aday et al., p. 175; production); and 4) efforts to advance technology or organizational productivity (dynamic efficiency).

FBO service-related research. Without establishment of effectiveness, allocative efficiency, and therefore production efficiency, cannot truly be assessed or guaranteed. However, a literature related to production efficiencies (such as capacity, cost-savings of volunteer workers, etc.) is developing (e.g., Chaves, Konieczny, Beyerlein, \& Barman, 1999; Chaves \& Tsitsos, 2001; Cnaan, Sinha, \& McGrew, 2004). Provided FBO service process issues such as intervention content, dose, and mechanism can be established and found to be effective, the emerging FBO production efficiency literature will be useful. It is worth noting, however, that empirically-based findings are showing less FBO capacity (production efficiency) than anticipated at the outset of the FBO initiatives (Kramer et al., 2005b). As a whole, FBO organizations have shown little desire to enter public-private service contracts and have struggled for the technical skills (e.g., grant writing, financial management, legal analysis, evaluation) required to do so (Kramer, 2010). National efforts are being made to address these technical gaps among FBOs (Exec. Order No. 13498, 2009; Kramer et al., 2005b). It will be important to evaluate how these efforts prospectively impact government contracting with FBOs. If and as empirical research addressing the effectiveness of FBO programs is available, efforts to entice FBOs to provide publicly funded social services, and the costs to develop their capacity to do so, can and should be assessed for allocative efficiency. 
FBO policy implementation considerations. There are a number of potential challenges to the efficient use of publicly funded FBO service providers, aside from the lack of prerequisite effectiveness evaluations. Per policy, people seeking services must be notified of their rights and any potential service patron who "objects to the religious character of an organization that provides services under the program, that organization shall, within a reasonable time after the date of the objection, refer the beneficiary to an alternative provider" (Exec. Order No. 13559, 2010, Sec.2.h.i). Further, the referring organization must assure the service seeker's actual connection with the alternative provider. Even the President's Council acknowledges "that implementing this recommendation could result in significant costs for the government. Nonetheless, Council members believe the government must take these steps in order to provide adequate protection for the fundamental religious liberty rights of social service beneficiaries” (President's Council, 2010, p. 141).

Aside from cost issues, the Principles and Policymaking Criteria policy (Exec. Order No. 13559, 2010) would seem implicitly to rely on the assumption that all communities are large enough to have: 1) duplication of equivalent services and 2) either at least one secular agency or such volume of FBO service programs that at least one organization's religious character will not be objectionable to a given client. What happens in the many communities that do not meet these assumptions? In those that do, by what standard are alternative service providers deemed acceptably equivalent (program outcomes; accessibility of location, operation hours, out-of-pocket costs; comprehensiveness of services offered; monetary value of services; etc)? Research indicating that some potential patrons find religious aspects of religiously-based programs distasteful (poor consumer satisfaction, e.g., Kissane, 2008; Sager \& Stephens, 2005) suggest that at least some people will request an alternative provider.

Policymakers, administrators, and social workers should be assessing their local municipalities to assess the best mix of services and providers in which they will invest to address local needs. All federal money allocated through the Partnerships with FaithBased and Other Neighborhood Organizations Office, be they direct (e.g., grants) or indirect (e.g., vouchers) payments, have administrative criteria regarding limitations on spending, expectations for fiscal accountability, and service process-related consumer rights and protections. Municipalities should stay attuned to current model guidance and regulations to help shape their own implementation processes and related staffing needs. Adherence to the administration and oversight guidelines of Partnerships with FaithBased and Other Neighborhood Organizations Office monies will require additional personnel time that must be accommodated. Lastly, organizations and municipalities accepting Partnerships with Faith-Based and Other Neighborhood Organizations Office funds might consider legal review of their obligations and duties.

\section{Equity}

Equity relates to fairness. Ultimately, equity is contingent upon assessing health disparities and assuaging them through effective and fair means. Effectiveness is an empirical criterion, but fair is a contested standard. Aday and colleagues (2004) distinguish between procedural equity and substantive equity. Procedural equity is 
concerned with the fairness of distribution of services and is tied to distributive justice and liberal political traditions. Considerations within this criteria include health-related policies, the delivery system (organization, availability, and financing), population characteristics (need, enabling, and predisposing factors), and realized access (utilization and satisfaction of actual and potential consumers). Distributive justice proponents will focus on the individual as the unit of equity analysis and prioritize values of costeffectiveness and freedom of choice. As such, it is associated with a more individualfocused, libertarian perspective. Distributive justice has guided much of our policy, and most of the health services research to date, but is criticized as failing to account for its inability to reduce health disparities in practice, the collective good of population health, and non-medical factors of health (Aday et al., 2004).

Substantive equity is concerned with the fairness of outcomes and relies upon social justice and communitarian principles. Whereas procedural equity is concerned with individual access and equal opportunity, substantive equity is concerned with community well-being and population-level outcomes. Accordingly, like social justice, substantive equity is concerned with fairness across population-level outcomes, with a focus on environmental factors (including social, physical, and economic) that foster or help reverse health disparities (Aday et al., 2004). Social justice proponents will prioritize the values of consideration of need across populations, the common good, and similar treatment outcomes.

Aday and colleagues (2004) conceptualize equity as derived through blending both of these traditions through deliberate discourse (reflecting deliberative democracy and justice principles wherein affected constituents use discourse to achieve mutual understanding and respect). Thus, the proposed concept of equity harmonizes procedural and substantive equity, yielding a model that provides both empirical and normative guidance for assessing FBOs. As Aday and colleagues summarize, "health policy making must take into account norms of distributive and social justice and that conflicts between affected stakeholders grounded in these contrasting norms must be resolved through deliberate discourse if the resultant policies are ultimately to contribute to improved health and minimizing health disparities. Both the effectiveness and equity criteria demand it” (p. 198). Aday and colleagues' (2004) blended concept of procedural equity (focused on individual access) and substantive equity (focused on population-level outcomes) provides a rigorous, comprehensive model for evaluating FBO policies, and, in particular, ensures that community-focused values are integral to the assessment.

Equity research may be descriptive (exploring dimensions), analytical, or evaluative. According to Aday and colleagues (2004), data for analyses may come from a number of sources. Service recipients may provide data through surveys, interviews, focus groups, or aggregated outcomes of official records. An institution's discrete service records such as walk-in clients, counts of particular services rendered, and financial accounting can provide data, as can personnel through surveys, interviews, focus groups, or employment records. Health care system records, such as funding or performance records, can provide data. Representative or purposeful survey sampling of community populations about health and health care utilization factors can produce data. Lastly, the community environment itself can provide invaluable data through physical measurements, 
observations, or reports about sociodemographic and physical environment health and health care use-related factors in a geographic region.

Aday and colleagues (1999) state: "The ultimate test of the equity of a health policy is the extent to which disparities or inequities in health persist among subgroups of the population” (p. SP41). This reveals a clear and consistent assumption that procedural equity (focused on equal access rather than equal outcomes) alone is an inadequate test for equity. They offer an in-depth discussion of justice theories and principles, along with corollary equity criteria and policy foci, that underpin the promoted distributive, social, and deliberative justices blended approach to equity that is beyond the scope of this article (Aday et al., 2004). However, their six equity criteria and related empirical indicators across these constructions of justice that underpin the recommended approach can be summarized and discussed. Health risks and health relate to the criterion of need. Development and implementation of Health policies will have inherent indicators about the criterion of participation of stakeholders (intended recipients, providers, general public). Health care delivery systems relate to the freedom of choice criterion. Realized access to health care relates to the criterion of cost-effectiveness. Treatment across populations at risk relates to the similar treatment criterion. And assessing the social, built, and natural environment for indicators of wellness relates to the common good criterion.

FBO service related research. From a research and scholarship perspective, Aday and colleagues' (2004) concept of equity advances the field in part by broadening the lens beyond traditional empirical social science methods. The framework draws upon philosophical theory and should include corollary methods, suggesting the need for crossdisciplinary training or multidisciplinary teams to address questions of equity. However, many of the empirical areas that Aday and colleagues suggest should inform equity discussions, track procedural equity concerns, and parallel or complement the kinds of data needed to answer questions of effectiveness and procedural efficiency (e.g., accounts of organizational characteristics or capacity, networks and systems of care, recipient characteristics, and satisfaction with services). Highlights of current FBO program research have been noted above. Observational population data analysis of the incidence of indicators of health, particularly those specifically targeted by the FBO initiatives (such as addiction, housing, and employment), can be used as indicators of social justice criteria when used to assess shifts in disparities among subgroups of the greater population.

On the scientific front, both the effectiveness and fairness components of FBO policies require attention. Field research and advancing research design or analytic methods will help progress the empirical outcomes component of the equity criterion. A second important agenda lays in efforts to use humanities methods to illuminate, explore, or advance the philosophical underpinnings of assumptions, methods, and conclusions of scientific evaluation of FBO programs and policies. This requires widening the lens for many, but is an important agenda if transparency and integrity of knowledge are the goals. Lastly, earnest and informed discussions among stakeholders are required for deliberative justice. Thus, dissemination of results of both these veins of research agendas will be important. 
FBO policy implementation considerations. Policymakers, administrators, social workers, and advocates will benefit from better breadth and depth of research, when available. The Aday and colleagues (2004) framework suggests equity should be determined through an earnest discussion among stakeholders as balance is sought between individual-level equity and populations-level concerns. This requires taking account of, and reconciling to constituent satisfaction, policies that foster fair dispersion and access of services, customer satisfaction, and cost-effectiveness (individual-level outcomes) on the one hand, with policies that foster enhanced community welfare, equality among populations, and collective good on the other hand.

It is worth noting that President Obama's creation of the President's Council and response to its recommendations suggests commitment to accountability and quality improvement of the policies and applications of federal funding of social services through FBOs. Applying Aday and colleagues' (2004) criteria for equity indicators of policy leads to mixed and inconclusive results. Need, one of Aday and colleagues' suggested policy equity criteria, is a driving force in the faith-based initiatives. There are multiple ecopsychosocial needs among the nation's vulnerable populations that go unmet, some of which are now targets of the FBO policies initiatives (Exec. Order No. 13498, 2009). This criterion is clearly met.

While intended or actual program recipients may have participated in various points of the process, the inaugural President's Council is comprised of twenty-five nongovernment organization, religious, and academic leaders. Deliberative democracy principles would suggest direct participation, with equal standing, by those intended to benefit from the programs. It is not readily clear that the participation equity criterion is currently met in FBO policy implementation.

The principle of freedom of choice is well represented in current policy statements. Efforts to correct implementation failures and assure religious freedom of program participants are underway (Exec. Order No. 13559, 2010). However this libertarian value is also aggressively being applied to rights of providers. A provider "may use [its] facilities to provide social services supported with Federal financial assistance, without removing or altering religious art, icons, scriptures, or other symbols from these facilities. . . [and] may maintain religious terms in its name, select its board members on a religious basis, and include religious references in its organization's mission statements and other chartering or governing documents,” (Exec. Order 13559, 2010, Sec.2.g). Thus, there are policies and measures being created to meet the equity criterion of freedom of choice - among both intended recipients and providers.

Aday and colleagues' (2004) equity consideration of cost-effectiveness is implicitly part of the current FBO policy and related regulatory effort. However, as noted above, this goal is currently problematic. Cost-efficiency falls within Aday and colleagues' (2004) conceptualization of efficiency and requires knowledge of effectiveness, which is not yet established. Further, policymakers will have to reconcile cost effectiveness goals against costs of policy services and implementation. Implementation costs might include those associated with: 1) technical training and recruitment of FBO partners; 2) assuring alternative providers are available for those service seekers who object to the religious 
character of an FBO program; 3) potential inefficiencies of directly supporting a service program that fails at realized access for a sub-group population - though using secondary (e.g., voucher) rather than primary (grant) funding mechanisms will help assuage this issue as payments follow use; and 4) administering and oversight of adherence to regulated service standards.

The similar treatment equity criterion suggests that people should receive comparable treatment for comparable needs, regardless of personal characteristics (e.g., age, race, income, or insurance). A key concern within this criterion is how FBO policies do or do not effectively increase access to and use of needed services (realized access). Are those accessing FBO services individuals who would not otherwise be served (e.g., would they go to a secular service provider?)? Alternatively, are FBO programs simply shifting the site of services among those already being served, thus failing to extend the reach of services and giving rise to the need to research how these consumers' outcomes compare between types of programs (an effectiveness issue)? The current policy effort seeks to meet the similar treatment equity criterion by dispersing services into organizations already embedded in communities, prohibiting providers from refusing clients based on a potential client's religious (or nonreligious) beliefs, and assuring an alternative provider will be made available to a potential client within a reasonable timeframe. These approaches are solid but may prove hard to effectively and efficiently implement and enforce.

A common good criterion perspective will be concerned with whether FBO policy improves social issue outcomes among the targeted vulnerable populations as compared to the general population. Common good is found in policies that increase "the social resources, or social capital, that may be available to individuals associated with the family structure, voluntary organizations, and social networks that both bind and support them" (Aday et al., 2004, p. 211). Within the frame of this equity criterion, perhaps FBO policy simply serves to enhance localized human capital and resources. If collective good is the policy equity criterion, then vitalizing communities of faith, irrespective of effectiveness or comparative effectiveness of their services upon individuals receiving them (so long as they are not doing harm), could satisfy this criterion. McMillin (2011) argues this is not what is happening, however. He raises concerns about contemporary churches abandoning communitarian values in favor of individualistic values and rhetoric. He argues churches are using these to advance their specific political and moral views through the leverage and platform of FBO social service program administration. Such behavior actually increases - rather than decreases - jeopardy of minority interests (McMillin, 2011). Irrespective, implementation challenges are likely as different segments of a given population compete for limited funds, effectively vying to be among those in the community most benefited by investments in the common good (De Vita \& Wilson, 2001; McMillin, 2011; Saperstein, 2003).

\section{DISCUSSION AND CONCLUSIONS}

Good policy is of concern to us as citizens and professional social workers, charged with critically analyzing and advocating about issues and policies impacting our clients 
and communities (CSWE, 2010). Federal policy changes have been shifting roles and responsibilities for social and safety net services downward and outward (Hutchison, 2011), including to FBOs, which may now maintain their religious identity as pervasively religious organizations while providing government-funded services.

Responsible assessment of the impact of the FBO policy is challenging. Most of the current literature consists of segmented research with limited scope, varied aims and standards for success (Johnson et al., 2008; Kramer, 2010; Kramer et al., 2005a), and conflation among types and funding sources of FBOs and their programs. Much of the public and professional discourse on the topic of FBO policies is narrow in focus, ideologically charged (Saperstein, 2003; Wineburg, 2007), familiar only to certain vested groups, and absent an appropriate conceptual framework. Moreover, the FBO policies are part of the devolution of public social and safety-net services (Kennedy, 2003; Mink, 2001; Wineburg et al., 2008) and reflect the new role religion has taken in politics (Gelman et al., 2010; McMillin, 2011). Setting aside the politics of this shift, it is clear that, consistent with its values and mission as a field, social work is responsible for evaluating FBO programs and policies through an analytic framework that includes the perspective of social justice and community well-being. Aday and colleagues' (2004) empirically supported, theoretically-based model, of the concepts of effectiveness, efficiency, and equity, provides such an analysis model.

A preliminary application of the model raises questions and concerns with current FBO policy. From the perspective of effectiveness, alongside administrators and policymakers, social workers should consider, for example, the need for nuanced population and dosing research among populations in order to determine how the added element of provider or setting's religiosity impacts social service outcomes. From the perspective of efficiency, alongside administrators and policymakers, social workers should consider, for example, whether the investment in services that requires additional expenditures (redundancy of alternative programs, and oversight management) is the best use of resources. From the perspective of equity, alongside administrators and policymakers, social workers should consider whether programs that emphasize and privilege a particular spiritual point of view provide better service, at the population level, than traditional secular programs that are responsive to the recipient's religious preferences. Aday and colleagues' (2004) equity concept demonstrates that there is a need for nuanced, community-specific research to identify where and for whom FBO programs may serve a population that cannot otherwise be successfully served, in order to assess where these programs may fit within a region's continuum of care.

Aday and colleagues' (2004) model is particularly helpful to, and compatible with, the field of social work, given its balanced concept of equity that incorporates both empirical and normative standards. Equity of outcome is empirical, but philosophies of equitable processes and values are contentious normative standards of central concern to social workers. Aday and colleagues (2004) offer an eloquent solution for issues of equity in health-related policies. They suggest that by balancing, through a deliberative discourse process (deliberative justice), the individual focus contained within the dominant distributive justice approach with the collective focus of the social justice approach (advanced in public health and social work), stakeholders can build effective 
policies along with trust and understanding. The present study contributes to this effort by introducing and using an established, theoretical, policy analysis framework, that is congruent with the values and the conceptualization of human behavior held by social workers (CSWE, 2010; NASW, 2008), to illuminate concerns with and launch discussion of federal FBO policies.

\section{References}

Aday, L. A., \& Andersen, R. M. (1974). A framework for the study of access to medical care. Health Services Research, 9, 208-220.

Aday, L. A., Begley, C. E., Lairson, D. R., Slater, C. H., Richard, A. J., \& Montoya, I. D. (1999). A framework for assessing the effectiveness, efficiency, and equity of behavioral healthcare. The American Journal of Managed Care, 5(special issues), sp25-sp44.

Aday, L. A., Begley, C. E., Lairson, D. R., \& Balkrishnan, R. (2004). Evaluating the healthcare system: Effectiveness, efficiency, and equity ( $3^{\text {rd }}$ ed.). Chicago: Health Administration Press.

Agency for Healthcare Research and Quality. (AHRQ). (2009). Preparing for a career in health services research (Rep. No. AHRQ Publication No. 09-P009). Retrieved from http://www.ahrq.gov/fund/minortrg.htm\#whatis

Amirkhanyan, A. A., Kim, H. J., \& Lambright, K. T. (2009). Faith-based assumptions about performance: Does church affiliation matter for service quality and access? Nonprofit and Voluntary Sector Quarterly, 38(3), 490-521. doi:10.1177/0899764008320031

Andersen, R. M. (1968). Behavioral model of families' use of health services. Research Series No. 25. Chicago: Center for Health Administration Studies, University of Chicago.

Andersen, R. M. (1995). Revisiting the behavioral-model and access to medical care: Does it matter? Journal of Health and Social Behavior, 36(1), 1-10.

Andersen, R. M. (2008). National health surveys and behavioral model of health services use. Medical Care, 46(7), 647-653. doi:10.1097/MLR.0b013e31817a835d

Ashton, C. M. (2008). An interview with Ronald Andersen, PhD. Medical Care, 46(7), 645-646. doi:10.1097/MLR.0b013e31817f4d48

Bartkowski, J. P., Call, V. R. A., Heaton, T. B., \& Forste, R. (2007). Religion, job readiness, and employment outcomes: The case of Latter-Day Saint employment resource services. Research on Social Work Practice, 17(2), 188-198. doi:10.1177/1049731506287074

Blackwell, C. W., \& Dziegielewski, S. F. (2005). The privatization of social services from public to sectarian: Negative consequences to America's gays and lesbians. Journal of Human Behavior in the Social Environment, 11(2), 25-41. doi:10.1300/J137v11n02_03 
Boerma, T., Chopra, M., \& Evans, D. (2009). Health systems performance assessment in the Bulletin. Bulletin of the World Health Organization, 87(1), 2-2.

doi:10.2471/BLT.08.061945. Retrieved from http://www.who.int/bulletin/volumes/87/1/08-061945/en/

Chaves, M., Konieczny, M. E., Beyerlein, K., \& Barman, E. (1999). The National Congregations Study: Background, methods, and selected results. Journal for the Scientific Study of Religion, 38(4), 458-476.

Chaves, M., \& W. Tsitsos (2001). Congregations and social services: What they do, how they do it, and with whom. Nonprofit and Voluntary Sector Quarterly, 30(4), 660683. doi:10.1177/0899764001304003

Cnaan, R. A., \& Boddie, S. C. (2002). Charitable choice and faith-based welfare: A call for social work. Social Work, 47(3), 224-235.

Cnaan, R. A., Sinha, J. W., \& McGrew, C. C. (2004). Congregations as social service providers: Services, capacity, culture, and organizational behavior. Administration in Social Work, 28(3-4), 47-68. doi:10.1300/J147v28n03_03

Cohen, A. B. (2009). Many forms of culture. American Psychologist, 64(3), 194-204. doi:10.1037/a0015308

Council on Social Work Education (CSWE). (2010). Educational policies and accreditation standards (EPAS). Retrieved from http://www.cswe.org/File.aspx?id=13780

De Vita, C. J., \& Wilson, S. (2001). Faith-based initiatives: Sacred deeds and secular dollars. Washington, DC: The Urban Institute, the Hauser Center Emerging Issues in Philanthropy Seminar Series. Retrieved from www.urban.org/url.cfm?ID=310351

DeHaven, M. J., Hunter, I. B., Wilder, L., Walton, J. W., \& Berry, J. (2004). Health programs in faith-based organizations: Are they effective? American Journal of Public Health, 94(6), 1030-1036. doi:10.2105/AJPH.94.6.1030

Department of Health \& Human Services Office of Minority Health (DHHS-OMH). (2005). What is Cultural Competency? Rockville, MD: Author. Retrieved from http://minorityhealth.hhs.gov/templates/browse.aspx?lvl=2\&lvlID=11

Dodson, K. D., Cabage, L. N., \& Klenowski, P. M. (2011). An evidence-based assessment of faith-based programs: Do faith-based programs "work" to reduce recidivism? Journal of Offender Rehabilitation, 50(6), 367-383. doi:10.1080/10509674.2011.582932

Ebaugh, H. R., Pipes, P. F., Chafetz, J. S., \& Daniels, M. (2003). Where's the religion? Distinguishing faith-based from secular social service agencies. Journal for the Scientific Study of Religion, 42(3), 411-426. doi:10.1111/1468-5906.00191

Edlund, M. J., Harris, K. M., Koenig, H. G., Han, X., Sullivan, G. M. R., \& Tang, L. (2010). Religiosity and the decreased risk of substance use disorders: Is the effect 
mediated by social support or mental health status? Social Psychiatry and Psychiatric Epidemiology, 45(8), 827-836. doi:10.1007/s00127-009-0124-3

Ehman, J. (2009). Spiritual assessment and health care: A select bibliography of Medline-indexed articles published 2001-2009. Retrieved from http://www.uphs.upenn.edu/pastoral/cpe/Res_Bib_Spiritual_Asessment_MEDLINE_ 2009.pdf

Exec. Order No. 13199, 66 Fed. Reg. 8,499 (2001). Retrieved from http://www.archives.gov/federal-register/executive-orders/disposition.html

Exec. Order No. 13498, 74 Fed. Reg. 6,533 (2009). Retrieved from http://www.archives.gov/federal-register/executive-orders/disposition.html

Exec. Order No. 13559, 75 Fed. Reg. 71,319 (2010). Retrieved from http://www.archives.gov/federal-register/executive-orders/disposition.html

Gelman, A., Park, D., Shor, B., \& Cortina, J. (2010). Red state, blue state, rich state, poor state: Why Americans vote the way they do (Expanded ed.). Princeton, NJ: Princeton University Press.

Government Accounting Office (GAO). (2002). Charitable choice: Overview of research findings on implementation. Report to Congressional requesters (Rep. No. GAO-02337). Washington, DC: Author. Retrieved from http://www.gao.gov/new.items/d02337.pdf

Government Accounting Office (GAO). (2006). Faith-based and community initiative; Improvements in monitoring grantees and measuring performance could enhance accountability. Report to Congressional requesters. (Rep. No. GAO-06-616). Washington, DC: Author. Retrieved from http://www.gao.gov/new.items/d06616.pdf

Green, J. C., \& Sherman, A. L. (2002). Fruitful collaborations: A survey of governmentfunded faith-based programs in 15 states. Charlottesville, VA: Hudson Institute, Inc. Retrieved from http://www.hudson.org/files/publications/fruitful_collab.pdf

Hackney, C. H., \& Sanders, G. S. (2003). Religiosity and mental health: A meta-analysis of recent studies. Journal for the Scientific Study of Religion, 42(1), 43-55. doi:10.1111/1468-5906.t01-1-00160

Hall, D. L., Matz, D. C., \& Wood, W. (2010). Why don’t we practice what we preach? A meta-analytic review of religious racism. Personality and Social Psychology Review, 14(1), 126-139. doi:10.1177/1088868309352179

Heslin, K. C., Andersen, R. M., \& Gelberg, L. (2003). Use of faith-based social service providers in a representative sample of urban homeless women. Journal of Urban Health: Bulletin of the New York academy of Medicine, 80(3), 371-382. doi:10.1093/jurban/jtg051

Hill, P. C., \& Pargament, K. I. (2003). Advances in conceptualization and measurement of religion and spirituality: Implications of physical and mental health research. American Psychologist, 58(1), 64-74. doi:10.1037/0003-066X.58.1.64 
Hodge, D. R. (2006). A template for spiritual assessment: A review of the JCAHO requirements and guidelines for implementation. Social Work, 51(4), 317-326.

Hodge, D. R., \& Pittman, J. (2003). Faith-based drug and alcohol treatment providers: An exploratory study of Texan providers. Journal of Social Service Research, 30(1), 1940. doi:10.1300/J079v30n01_02

Hutchison, E. D. (2011). Social structure and social institutions: Global and national. In E. D. Hutchison (Ed.), Dimensions of human behavior: Person and environment ( $4^{\text {th }}$ ed., pp. 210-239). Los Angeles: Sage.

Jeavons, T. H. (1998). Identifying characteristics of "religious" organizations: An exploratory proposal. In N. J. Demerath III, Hall, P. D., Schmitt, T., and Williams, R. H. (Eds.), Sacred companies: Organizational aspects of religion and religious aspects of organizations (pp. 79-95). New York: Oxford University Press.

Jeavons, T. H. (2004). Religious and faith-based organizations: Do we know one when we see one? Nonprofit and Voluntary Sector Quarterly, 33(1), 140-145. doi:10.1177/0899764003257499

Johnson, B. R., Tompkins, R. B., \& Webb, D. (2008). Objective hope: Assessing the effectiveness of faith-based organizations: A review of the literature. Baylor Institute for Studies of Religion Report. A reissuance of a University of Pennsylvania CRRUCS 2002 report. Retrieved from www.baylor.edu/content/services/document.php/24809.pdf

Just the Facts Coalition. (2008). Just the facts about sexual orientation and youth: A primer for principals, educators, and school personnel. 114 Washington, DC: American Psychological Association. Retrieved from http://www.apa.org/pi/lgbt/resources/just-the-facts.pdf

Kennedy, S. S. (2003). Privatization and prayer: The challenge of charitable choice. American Review of Public Administration, 33(1), 5-19. doi:10.1177/0275074002250253

Kissane, R. J. (2008). How do faith-based organizations compare to secular providers? Nonprofit directors' and poor women's assessments of FBOs. Journal of Poverty, 11(4), 91-115. doi:10.1300/J134v11n04_05

Kramer, F. D. (2010). The role for public funding of faith-based organizations delivering behavioral health services: Guideposts for monitoring and evaluation. American Journal of Community Psychology, 46(3-4), 342-360. doi:10.1007/s10464-010-93518

Kramer, F. D., Finegold, K., De Vita, C. J., \& Wherry, L. (2005a). Federal policy on the ground: Faith-based organizations delivering local services (Rep. No. 05-01). The Urban Institute, Discussion Papers of the Assessing the New Federalism project. Retrieved from www.urban.org/uploadedPDF/311197_DP05-01.pdf

Kramer, F. D., Finegold, K., De Vita, C. J., \& Wherry, L. (2005b). Implementing the Federal faith-based agenda: Charitable Choice and Compassion Capital initiatives 
(Rep. No. Series A, the New Federalism: Issues and Options for States, No. A-69). Washington, DC: The Urban Institute. Retrieved from www.urban.org/publications/311274.html

Levy, D. L., \& Reeves, P. (2011). Resolving identity conflict: Gay, lesbian and queer individuals with Christian upbringing. Journal of Gay \& Lesbian Social Services, 23(1), 53-68. doi:10.1080/10538720.2010.530193

Lyons, G. C. B., Deane, F. P., \& Kelly, P. J. (2010). Forgiveness and purpose in the life as spiritual mechanism of recovery from substance use disorder. Addiction Research and Theory, 18(5), 528-543. doi:10.3109/16066351003660619

Lyons, J. S., Howard, K. I., O'Mahoney, M. T., \& Lish, J. D. (1997). The measurement and management of clinical outcomes in mental health. New York: John Wiley \& Sons.

Mattison, D., Jayaratne, S., \& Croxton, T. (2000). Social workers' religiosity and its impact on religious practice behaviors. Advances in Social Work, 1(1), 43-59. Retrieved from http://advancesinsocialwork.iupui.edu/index.php/advancesinsocialwork/article/view/1 $\underline{02 / 92}$

McKay, R., Efferson, C., Whitehouse, H., \& Fehr, E. (2010). Wrath of God: Religious primes and punishment. Proceedings of the Royal Society B.E-published on line in advance of the print version, 1-7. doi:10.1098/rspb.2010.2125. Retrieved from http://rspb.royalsocietypublishing.org/content/early/2010/11/17/rspb.2010.2125.full.p $\underline{\mathrm{df}+\mathrm{html}}$

McMillin, S. E. (2011). Faith-based social services: From communitarian to individualistic values. Zygon, 46(2), 482-490. doi: 10.1111/j.14679744.2010.01189.x

Mink, G. (2001). Faith in government? Social Justice, 28(1), 5-10. Retrieved from http://www.jstor.org/stable/29768054

National Association of Social Workers (NASW). (2008). Code of ethics of the National Association of Social Workers. Retrieved from http://www.socialworkers.org/pubs/code/code.asp

Netting, F. E. (2004). Commentary on typology of religious characteristics of social service and educational organizations and programs. Nonprofit and Voluntary Sector Quarterly, 33(1), 135-139. doi:10.1177/0899764003257495

O'Connor, M. K., \& Netting, F. E. (2008). Faith-based evaluation: Accountable to whom, for what? Evaluation and Program Planning, 31(4), 347-355.

doi:10.1016/j.evalprogplan.2008.04.013

Obama, B. (n.d.). Preserving our constitutional commitments and values. Office of Faithbased and Neighborhood Partnerships, The White House. Retrieved from http://www.whitehouse.gov/administration/eop/ofbnp/values 
Pargament, K. I., Zinnbauer, B. J., Scott, A. B., Butter, E. M., Zerowin, J., \& Stanik, P. (1998). Red flags and religious coping: Identifying some religious warning signs among people in crisis. Journal of Clinical Psychology, 54(1), 77-89. doi:10.1002/jclp.10225

Park, C. L. (2007). Religiousness/spirituality and health: A meaning systems perspective. Journal of Behavioral Medicine, 30(4), 319-328. doi:10.1007/s10865-007-9111-x

Pew Forum on Religion \& Public Life (PEW). (2009). Faith-based programs still popular, democrats now more supportive than republicans. Washington, DC: Pew Research Center for the People \& the Press. Retrieved from http://pewresearch.org/pubs/1412/faith-based-programs-popular-church-stateconcerns

Phillips, K. A., Morrison, K. R., Andersen, R., \& Aday, L. A. (1998). Understanding the context of healthcare utilization: Assessing environmental and provider-related variables in the behavioral model of utilization. Health Services Research, 33(3), 571-596. Retrieved from http://www.ncbi.nlm.nih.gov/pmc/articles/PMC1070277/pdf/hsresearch000270142.pdf

Powell, L. H., Shahabi, L., \& Thoresen, C. E. (2003). Religion and spirituality: Linkages to physical health. American Psychologist, 58(1), 36-52. doi:10.1037/0003066X.58.1.36

President's Advisory Council on Faith-based and Neighborhood Partnerships (President's Council). (2010). A new era of partnerships: Report of recommendations to the president Washington, DC: The White House. Retrieved from http://www.whitehouse.gov/partnerships

Preston, J. L., Ritter, R. S., \& Hernandez, J. I. (2010). Principles of religious prosociality: A review and reformulation. Social and Personality Psychology Compass, 4(8), 574590. doi:10.1111/j.1751-9004.2010.00286.x

Reingold, D. A., Pirog, M., \& Brady, D. (2007). Empirical evidence on faith-based organizations in an era of welfare reform. Social Service Review, 81(2), 245-283. doi:10.1086/515832

Rowatt, W. C., LaBouff, J., Johnson, M., Froese, P., \& Tsang, J. A. (2009). Associations among religiousness, social attitudes, and prejudice in a national random sample of American adults. Psychology of Religion and Spirituality, 1(1), 14-24. doi:10.1037/a0014989

Sager, R., \& Stephens, L. (2005). Serving up sermons: Clients’ reactions to religious elements at congregation-run feeding establishments. Nonprofit and Voluntary Sector Quarterly, 34(3), 297-315. doi:10.1177/0899764005275203

Saperstein, D. (2003). Public accountability and faith-based organizations: A problem best avoided. Harvard Law Review, 116(5), 1353-1396. Retrieved from www.jstor.org/stable/1342729 
Seeman, T. E., Dubin, L. F., \& Seeman, M. (2003). Religiosity/spirituality and health: A critical review of the evidence for biological pathways. American Psychologist, 58(1), 53-63. doi:10.1037/0003-066X.58.1.53

Seybold, K. S. (2007). Physiological mechanisms involved in religiosity/spirituality and health. Journal of Behavioral Medicine, 30(4), 303-309. doi:10.1007/s10865-0079115-6

Sherry, A., Adelman, A., Whilde, M. R., \& Quick, D. (2010). Competing selves: Negotiating the intersection of spiritual and sexual identities. Professional Psychology: Research and Practice, 41(2), 112-119. doi:10.1037/a0017471

Sider, R. J., \& Unruh, H. R. (2004). Typology of religious characteristics of social service and educational organizations and programs. Nonprofit and Voluntary Sector Quarterly, 33(1), 109-134. doi:10.1177/0899764003257494

Smith, S. R. \& Sosin, M. R. (2001). The varieties of faith-based social service programs: Types and integrative strategies. Public Administration Review, 61(6), 651-669. doi:10.1111/0033-3352.00137

Sternthal, M. J., Williams, D. R., Musick, M. A., \& Buck, A. C. (2010). Depression, anxiety, and religious life: A search for mediators. Journal of Health and Social Behavior, 5(3), 343-359. doi:10.1177/0022146510378237

Substance Abuse and Mental Health Services Administration (SAMHSA). (2008). National survey of substance abuse treatment services (N-SSATS) (Rep. No. OMB No. 0930-0106). Princeton, NJ: Mathematica Policy Research, Inc. Retrieved from http://wwwdasis.samhsa.gov/dasis2/nssats/nssats_2008_q.pdf

Substance Abuse and Mental Health Services Administration (SAMHSA), Office of Applied Studies. (2010, September 2). The N-SSATS Report, Substance abuse treatment facilities affiliated with a religious organization (Rep. No. N-SSATS_244). Rockville, MD: Author. Retrieved from http://www.samhsa.gov/data/2k10/244FaithBased2k10Web/244FaithBased2k10web. pdf

Sung, H. D., Chu, D., Richter, L., \& Shlosberg, A. (2009). Treatment philosophy and service delivery in a network of faith-based substance abuse treatment. Families in Society, 90(4), 390-398. doi:10.1606/1044-3894.3925

Tangenberg, K. M. (2005). Faith-based human services initiatives: Considerations for social work practice and theory. Social Work, 50(3), 197-206.

Unruh, H. R. (2004). Religious elements of church-based social service programs: Types, variables and integrative strategies. Review of Religious Research, 45(4), 317-335.

UW Department of Health Services. (2011). What is health services research? Seattle: University of Washington. Retrieved from http://depts.washington.edu/hserv/hsresearch-definitions 
Wakefield, J. C. (1996). Does social work need the eco-systems perspective? Part 1. Is the perspective clinically useful? Social Service Review, 70(1), 1-32. Retrieved from http://www.jstor.org/stable/30012588

Webb, J. R., Robinson, E. A. R., \& Brower, K. J. (2011). Mental health, not social support, mediates the forgiveness-alcohol outcome relationship. Psychology of Addictive Behaviors. doi:10.1037/a0022502

Whitley, B. E. Jr. (2009). Religiosity and attitudes toward lesbians and gay men: A metaanalysis. The International Journal for Psychology of Religion, 19, 21-38. doi:10.1080/10508610802471104

Wineburg, B. (2007). Faith-based inefficiency, the follies of Bush's initiatives. Westport: CT: Praeger Publishers.

Wineburg, R. J., Coleman, B. L., Boddie, S. C., \& Cnaan, R. A. (2008). Leveling the playing field: Epitomizing devolution through faith-based organizations. Journal of Sociology \& Social Welfare, 35(1), 17-42.

Wuthnow, R., Hackett, C., \& Hsu, B. Y. (2004). The effectiveness and trustworthiness of faith-based and other service organizations: A study of recipients' perceptions. Journal for the Scientific Study of Religion, 43(1), 1-17. doi:10.1111/j.14685906.2004.00214.x

\section{Author note}

Address correspondence to: Michelle D. Garner, PhD, ACSW, LICSW, University of Washington Tacoma, 1900 Commerce Street, Tacoma, WA, 98402. Email:

mdgarner@u.washington.edu 